\title{
Drying of Strawberry in a Direct and Indirect Solar Dryer (Effects of Drying Methods on Total Phenolic Content)
}

\author{
López-Vidaña Erick César, Pilatowsky Figueroa Isaac, and Navarro-Ocaña Arturo
}

\begin{abstract}
During the drying process, foods undergo irreversible chemical and physical changes and the operational conditions determine the final quality of the product. In this work, the drying kinetics of strawberry in a direct (DSD) and indirect solar dryers (ISD) and total phenolic and anthocyanin content of strawberries after solar drying process were determined.

The present study demonstrates, how the solar drying affects the total phenolic content of the samples. It was observed that the samples exposed to direct solar irradiance, were the most affected, while those who were not exposed, were less affected. This could help the food industry to find a better technic to dehydrate keeping their antioxidant properties and to provide added value and quality.
\end{abstract}

Keywords - Strawberry, Solar drying, Total Phenolic Content.

\section{INTRODUCTION}

$\mathrm{S}_{\mathrm{v}}^{\mathrm{T}}$ TRAWBERRY are largely consumed perishable fruits with high economic value and healthy nutrients [1]. They are a rich source of ascorbic acid and antioxidants such as anthocyanins. In addition to natural coloring properties, interest in anthocyanins has intensified because of their possible role in hypertension prevention and reducing the risk of coronary heart disease, cancer and stroke [2].

Drying is a common industrial procedure to obtain products with reduced moisture content which are easy to store and transport. During this process, food quality loss is linked to the use of high temperatures and long drying times. By other hand, after drying, numerous physical and chemical changes can negatively or positively affect their nutritional and sensorial properties [3]. Thus, the limitations to a conventional drying process could be partially overcome by using other type of energy sources, such as solar, heat waste and geothermal. Moreover, the fact that applying solar energy produces a low thermal effect with a high interest of its

López-Vidaña Erick César, Posgrado en Ingeniería - Energía, Instituto de Energías Renovables -UNAM, Morelos, México.

Pilatowsky Figueroa Isaac, Laboratorio de Secado Solar, Instituto de Energías Renovables-UNAM, Morelos, México.

Navarro-Ocaña Arturo, Departamento de Ciencias de los Alimentos y Biotecnología, Facultad de Química- UNAM, D.F., México. application in the drying of heat-sensitive materials.

Therefore, the food industry is looking for new alternative, inexpensive preservation methods yielding minor alterations on the main attributes of fruits processed [4]. Strawberries are highly perishable, and solar drying is an alternative that can be to extend their shelf-life.

\section{METHODS}

The tests were performed at Instituto de Energías Renovables, from Universidad Nacional Autónoma de México in Temixco, Morelos, México; located at $18^{\circ} 51^{\prime}$ of NL and 99 $14^{\prime}$ of WL, with maximum average values of solar irradiance of 990 $\mathrm{W} / \mathrm{m} 2$.

\section{A. Raw materials}

The Strawberries were obtained in good physical conditions and adequate degree of ripeness and were sliced into $8 \mathrm{~mm}$, its initial moisture content was $9.7 \pm 0.08 \mathrm{~g} \mathrm{H} 2 \mathrm{O} /$ $\mathrm{g}$ dry matter. The fruits were treated with a solution of chlorine $(100 \mathrm{ppm})$ to remove dirt and then were stored under refrigeration at $-5^{\circ} \mathrm{C} \pm 0.5^{\circ} \mathrm{C}$ before the dehydration process.

\section{B. Data acquisition}

Incident global solar radiation was recorded on a local level using a Keep and Zonnen pyranometer with a sensitivity

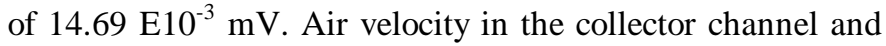
drying chamber, as well as wind speed on the surface of the collector, were measured using a Hot-Wire ThermoAnemometer (Cole-Parmer) with an accuracy of $\pm 0.03 \mathrm{~m} / \mathrm{s}$. Temperature and solar radiation were recorded every $15 \mathrm{~min}$ using a computer connected to Agilent data acquisition system and hp Vee software. Type $\mathrm{J}$ thermocouples with a accuracy of $\pm 0.1{ }^{\circ} \mathrm{C}$ were placed in the drying chamber.

\section{Direct Solar dryer (DSD)}

The direct solar dryer (DSD), consists of a chamber constructed of transparent plastic, with holes in the base and on the sides to allow the air-hot-humid outside circulation by natural convection. The dryer has a catchment area of 0.48 $\mathrm{m}^{2}$.

Drying kinetics at natural convection were obtained. Slices of strawberry were previously cleaned and disinfected and 
werw placed on the black trays in the dryer chamber. Which receive solar radiation directly. The air is heated by the greenhouse effect, then it is moistened and ejected through the side and bottom holes.

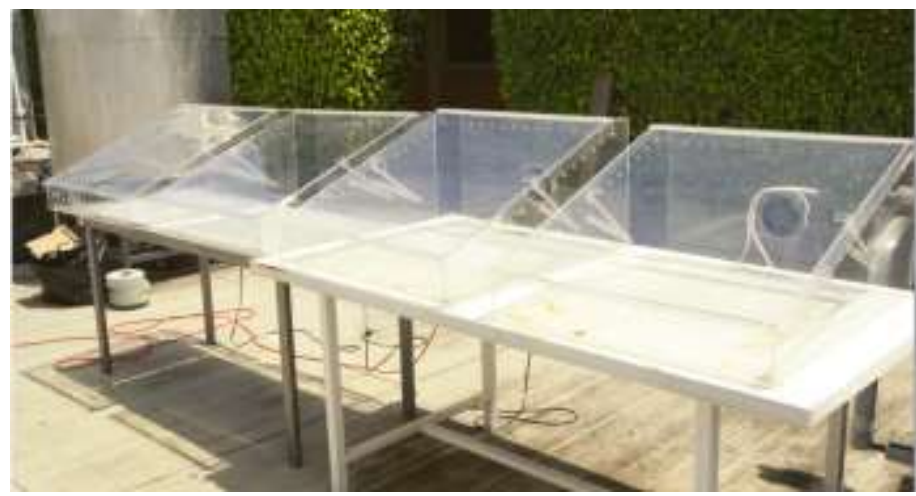

Fig. 1: Direct Solar Dryers

\section{D.Indirect Solar dryer (ISD)}

Solar drying indirect WAS designed to establish the conditions of temperature and air velocity required for a wide variety of foods. This ISD can be operated during the day, night and day and night. The combined solar dryer (photothermal-photovoltaic) consists of a horizontal rectangular tunnel with a constant flow section, where in air is circulated by natural or forced way [5]. The air is heated by direct (DSTS) and indirect (ISTS) solar thermal systems. The DSTS, consist in a solar air heating collector and ISTS consist in an air- solar water heat exchanger.

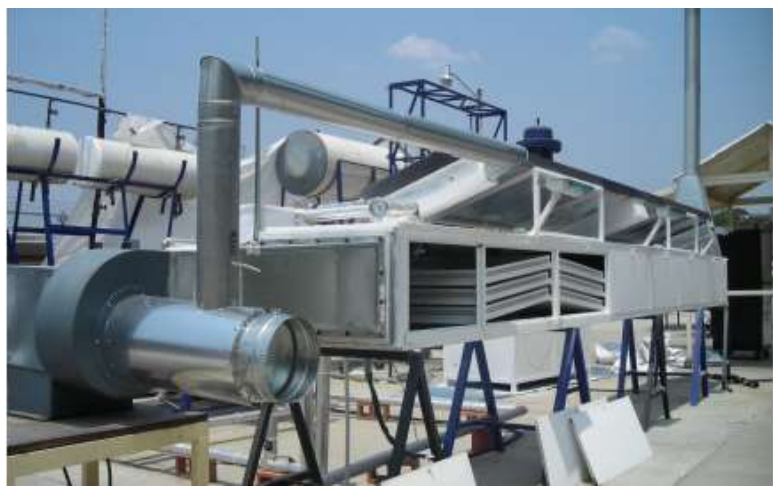

Fig. 2: Indirect Solar Dryer

\section{E. Determination of Total Phenols Content (Follin - Ciocalteu)}

The total phenolic content was determined using the adapted Follin-Ciocalteu method [6]. The extracts of the fruit $(50 \mu \mathrm{L})$ were mixed with $125 \mu \mathrm{L}$ of Follin-Ciocalteu reagent and $400 \mu \mathrm{L}$ of a solution of sodium carbonate $(7.1 \% \mathrm{w} / \mathrm{v})$, and the resulting solution was brought to a final volume of $1000 \mu \mathrm{L}$. The mixture was stirred and stored at room temperature for 30 minutes in darkness. The absorbance was measured at $760 \mathrm{~nm}$ against a blank. Aqueous solutions of gallic acid were used for the calibration curve. The results are expressed as mg of gallic acid equivalents (GAe) / g extract.

\section{RESULTS AND DISCUSSION}

\section{A. Drying experiments}

The experimental results of solar drying kinetics are shown in Figs. 3 and 4. Figure 3 shows the drying curves obtained on DSD and ISD. Concerning the drying time, in the case of ISD the time is lower, as it offers a greater flow of hot air. At the end of drying time the two methods provide a final moisture content similar but at different times, being shorter with the ISD process ( $0.05 \mathrm{~g}$ water / dry basis). Reaching the equilibrium moisture content at 5 hours while in the other method (DSD), the approximate time was 7 hours.

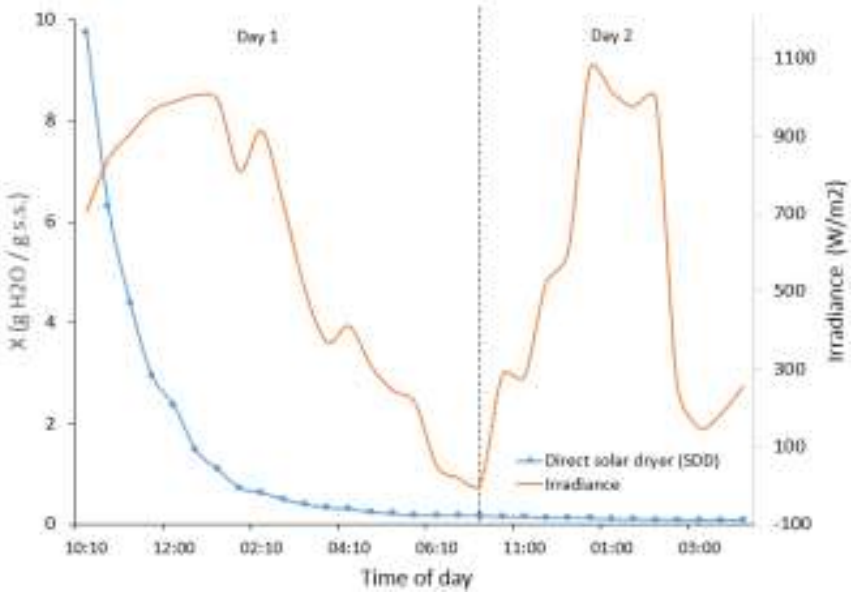

Fig. 3: Irradiance vs Moisture Content (DSD)

At the end of the drying process the moisture content was 0.219 and $0.184 \mathrm{~g} \mathrm{H} 2 \mathrm{O} / \mathrm{g}$ dry matter in DSD and ISD respectively and the final thickness was approximately 1.4 $\mathrm{mm}$.

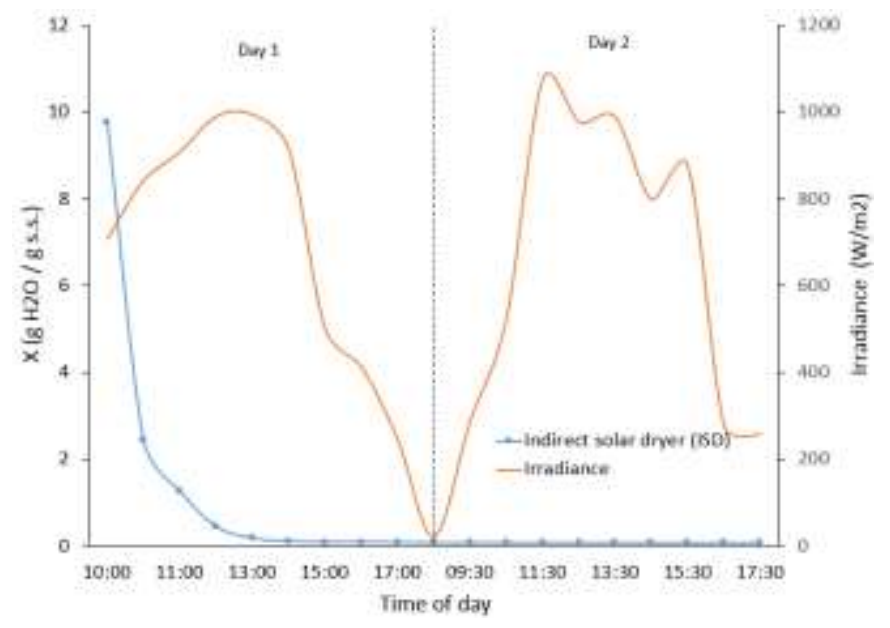

Fig. 4: Irradiance vs Moisture Content (ISD)

In both experiments, the maximum solar radiation is about $990 \mathrm{~W} / \mathrm{m} 2$. The maximum temperature reached in the indirect solar dryer (ISD) was $48{ }^{\circ} \mathrm{C}$, while the direct solar dryer (DSD) was $52^{\circ} \mathrm{C}$. 


\section{B. Determination of Total Phenols Content (Follin - Ciocalteu)}

Figure 5 present the results of the total phenols content after drying time (420 minutes), the results shown that the phenols is preserved in more amount when the solar radiation incident directly on the strawberry slices.

The experimental results were compared with the content of phenols found in lyophilized samples, by the fact that its characteristics are as close to fresh fruit. Freeze-dried products are dry, light and porous, almost retaining their original shape and texture [7]. In this work the lyophilized reference fruit content of total phenols was taken.

Is also noted that the samples subjected to direct solar drying, were affected in $82 \%$ respect to the initial content of phenols. While the indirect solar drying, were affected in 90\% respect to the initial content of phenols. In the drying cabinet (DSD) was best preserved (17.66 mg GAe/ g extract), while in the solar drying tunnel (IDS) the anthocyanins was lower (10.49 mg GAe/ g extract).

This behavior could be attributed to polyphenols that in an intermediate stage of oxidation have greater antioxidant capacity than initially or also to high temperature stabilization procedures that may lead to the formation of new compounds with higher antioxidant activity [8].

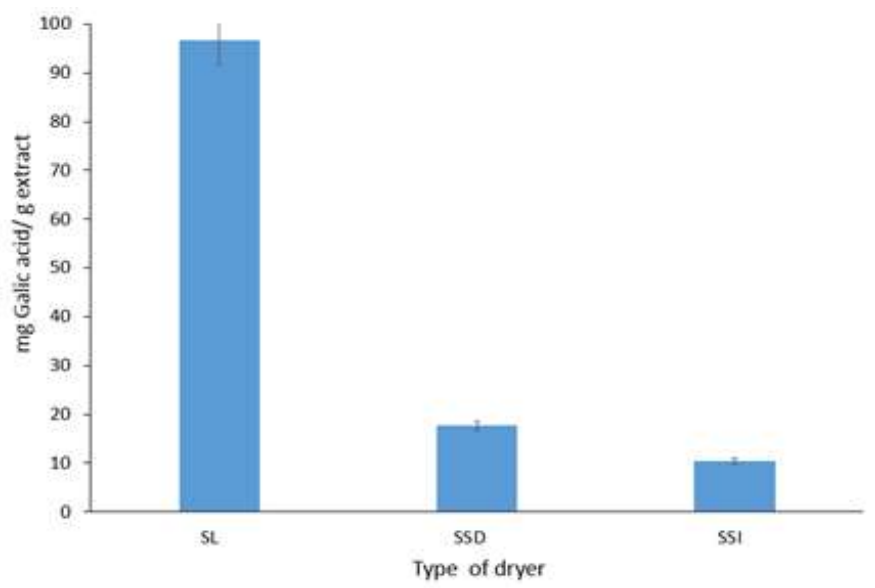

Fig. 5: Total phenols content of fresh and dried strawberries

\section{CONCLUSIONS}

Then, the total phenol content in the DSD was higher than in the ISD. Contrary to what was expected, the solar radiation and the temperature reached within the drying chamber, able to keep at greater than phenols present in the fruit. There may be several factors that can cause these results, such as: air flow, temperature and solar radiation mostly used directly or indirectly on the food form.

In subsequent experiments, control each of the variables involved will have to determine which the determining factor in the final quality of the dried strawberries solar methods.

\section{ACKNOWLEDGMENT}

We thank at the Universidad Nacional Autónoma de México and Consejo Nacional de Ciencia y Tecnología (CONACyT) for financial support for attending the conference as well as the company "VidaFrut" for the donation of raw material for the present study.

\section{REFERENCES}

[1] Shi, J., Pan, Z., McHugh, T. H., Wood, D., Hirschberg, E., \& Olson, D. (2008). Drying and quality characteristics of fresh and sugar-infused blueberries dried with infrared radiation heating. LWT - Food Science and Technology, 41(10), 1962-1972. doi:10.1016/j.lwt.2008.01.003

[2] Hernández-Herrero, J. a, \& Frutos, M. J. (2014). Colour and antioxidant capacity stability in grape, strawberry and plum peel model juices at different $\mathrm{pHs}$ and temperatures. Food Chemistry, 154, 199-204. doi:10.1016/j.foodchem.2014.01.007

[3] Gamboa-Santos, J., Montilla, A., Soria, A. C., Cárcel, J. a, García-Pérez, J. V, \& Villamiel, M. (2014). Impact of power ultrasound on chemical and physicochemical quality indicators of strawberries dried by convection. Food Chemistry, 161, 40-6. doi:10.1016/j.foodchem.2014.03.106

[4] De Bruijn, J., \& Bórquez, R. (2014). Quality retention in strawberries dried by emerging dehydration methods. Food Research International, 63, 42-48. doi:10.1016/j.foodres.2014.03.029

[5] Gama, David. (2007). Análisis teórico-experimental de un deshidratador solar combinado (térmico-fotovoltaico) para el tratamiento de arroz. Tesis de maestría, CIE-UNAM

[6] Singleton, V. L., Rossi, J. A. (1965). Colorimetry of total phenolics with phosphomolybdic-phosphotungstic acid reagents. J. Enol. Vitic, 16, 14458.

[7] Barbosa-Cánovas G., Ortega-Rivas E., Juliano P. and Yan H., 2005. Food Powders, Physical Properties, Processing, and Functionality. Kluwer Academic/Plenum Publishers New York, ISBN 0-306-47806-4

[8] Piga, A., Del Caro, A., Corda, G. (2003). From plums to prunes: Influence of drying parameters on polyphenols and antioxidant activity. J. Agric. Food Chem, 51, 3675-3681. 